\title{
OS SABERES TRADICIONAIS DOS INDÍGENAS KAIOWÁ DE DOURADOS-MS: transformações culturais através do tempo
}

\section{THE TRADITIONAL KNOWLEDGE OF INDIGENOUS KAIOWÁ OF DOURADOS-MS: cultural interferences through the time}

\author{
LOS CONOCIMIENTOS TRADICIONALES DE LOS INDÍGENAS \\ KAIOWÁ DE DOURADOS-MS: transformaciones culturales con el tiempo
}

\author{
Djanires Lageano de Jesus \\ Doutorando do Programa de Pós-Graduação em Geografia da UFPR. Docente e Pesquisador da \\ UEMS. Bolsista de Doutorado da FUNDECT-MS. Rua Manoel Olegário da Silva, 409, Jd. Itatiaia, \\ Campo Grande-MS, CEP 79840-020. \\ E-mail: netoms@uems.br
}

Marina Evaristo Wenceslau

Doutora em História pela USP. Docente e Pesquisadora da Universidade Estadual de Mato Grosso do Sul - UEMS. Rua Joaquim A. Taveira, 3588, Dourados-MS, CEP: 79825060.

E-mail: marinaew@uol.com.br

\section{Resumo}

O presente artigo tem como objetivo socializar um estudo sobre a evolução bem como os efeitos provocados ao longo do tempo nos saberes tradicionais das comunidades indígenas Kaiowá, habitantes da Reserva Indígena de Dourados. A fundamentação da pesquisa foi obtida por meio de pesquisa bibliográfica, documental e de campo junto à comunidade estudada. Os resultados parciais sinalizam que os indígenas em detrimento da globalização vêm sofrendo interferências significantes no modo de ser tradicional, ou seja, os induz na necessidade de reconfiguração cultural para lutar por seu reconhecimento étnico bem como a inclusão social.

Palavras-chave: Tradição, Território, Kaiowá, Desenvolvimento cultural.

\begin{abstract}
The main objective of this article is to socialize a study on the evolution and the resulting effects over time on traditional knowledge of indigenous communities Kaiowá, inhabitants of the Reserva Indígena de Dourados, Mato Grosso do Sul State, Brazil. The rationale of the research was obtained through literature, documentary and field in the community studied. Partial results indicate that the indigenous people at the expense of globalization have been suffering significant interference in the traditional way of being that induces the need for reconfiguration to fight for cultural recognition ethnic and social inclusion.
\end{abstract}

Keywords: Tradition, Territory, Kaiowá, Cultural Development. 


\section{Resumen}

Este artículo tiene como objetivo socializar un estudio sobre la evolución y los efectos resultantes en el tiempo sobre los conocimientos tradicionales de las comunidades indígenas Kaiowá, habitantes de la Reserva Indígena de Dourados, Mato Grosso do Sul, Brasil. La justificación de la investigación se obtuvo a través de la literatura, documental y de campo en la comunidad estudiada. Los resultados parciales indican que los indígenas a expensas de la globalización han estado sufriendo interferencias significativas en la forma tradicional de ser, es decir, induce la necesidad de reconfiguración de luchar por el reconocimiento cultural de inclusión étnica y social. Palabras-clave: Tradición, Territorio, Kaiowá, Desarrollo Cultural.

\section{INTRODUÇÃO}

As dinâmicas territoriais indígenas são marcadas pela subjetividade do território que o reconheça como um espaço contíguo em que aflora as emoções e perpetua a história vivida em um local, o que se aplica devidamente aos exemplos das comunidades indígenas residentes da Reserva Indígena de Dourados - RID, mais precisamente sobre os Kaiowá, no estado de Mato Grosso do Sul, Brasil. Portanto, a questão que envolve tais territórios denota a tomada de consciência cognitiva e física, para tais categorias, ao considerar um processo de litígio histórico, embutido de territorialidade ao atribuir-lhe sentimento de pertença ao grupo e ao espaço utilizado.

A discussão sobre a territorialidade potencializa o estudo do espaço bem como aos recursos naturais, organização social e econômica, sistemas de valores de uso e simbologia como um fator primordial para a construção da própria identidade do grupo, neste caso, da comunidade Kaiowá. O processo de territorialização dos grupos indígenas ao mobilizarem um sentido de coletividade organizada acaba por unificar uma identidade própria que incide em sua representação e reestruturação de suas formas culturais (OLIVEIRA, C.M, 1998).

Pelo passado histórico e sócio-espacial, é essencial destacar um isolamento característico que condiz à realidade de grupos indígenas identificados no Brasil. Embora toda regra tenha sua exceção, seria imprudente afirmar que todos os núcleos estejam localizados somente em áreas rurais, haja vista que se pode encontrá-los em zonas periurbanas e até mesmo nas grandes cidades. O importante é destacar que a 
integridade cultural e identitária sejam consideradas como mecanismos de fortalecimento e reforçadas através de gerações.

Ao mesmo tempo, cabe ressaltar que independente da localização e da questão de territorialidade física e emocional, muitos grupos étnicos buscam alternativas para promover uma gestão de inclusão do território com base no desenvolvimento de atividades que possam promulgar níveis significativos de melhorias baseados, sobretudo, na endogenia e fluxo cultural local para evidenciar sua alteridade cultural. Desta forma, as relações territoriais indígenas são expressões marcantes e complexas ligadas diretamente a sua identidade cultural. O território incorpora as expressões dos modos de vida tanto do passado, como do presente, contendo, ao mesmo tempo, significados culturais residuais e emergentes.

O presente trabalho não objetiva atribuir juízo de valor sobre o que poderia ser feito ou como os Kaiowá deveriam fazer para preservar sua alteridade cultural. Analisase o processo de evolução da cultura indígena da RID a fim de diagnosticar como sua representação cultural tem sido modificada ao longo do tempo. Nesse sentido, foram promovidas reflexões teóricas e conceituais identificadas por meio de leituras, fichamentos, além de diagnóstico identificado no local por meio de entrevistas com indígenas Guarai-Kaiowá diante dos efeitos provocados em sua tradição.

O que se espera com o presente artigo, portanto, é promover uma reflexão que segue a linha do tempo sobre o processo de tradicionalização da cultura indígena GuaraniKaiowá, mais precisamente dos povos de comungam um espaço territorial exíguo para sobrevivência sociocultural de três grupos distintos que habitam a RID. Desta forma, como a RID em questão, se constitui das etnias Kaiowá, Nandeva, Terena além dos mestiços, o presente trabalho irá tratar, do primeiro povo citado.

\section{As dinâmicas territoriais indígenas como expressão cultural}

Para entender as relações territoriais é necessário definir claramente o que é território. Segundo Santos, incorporando esta concepção territorial à relação com identidade que, no caso, facilita o entendimento das relações indígenas, observa-se que:

O território não é apenas o conjunto dos sistemas naturais e de sistemas de coisas superpostas. O território tem que ser entendido como o território usado, 
não o território em si. O território usado é o chão mais a identidade. A identidade é o sentimento de pertencer àquilo que nos pertence. O território é o fundamento do trabalho, o lugar da resistência, das trocas materiais e espirituais e do exercício da vida (SANTOS, 2002, p. 9-10).

As questões territoriais indígenas, no caso dos povos habitantes do estado de Mato Grosso do Sul, estão relacionadas ao compartilhamento da cultura entre as diversas etnias existentes, que mesmo possuindo características distintas, estão agrupados em aldeias e/ou reservas, loteamentos urbanos e áreas urbanas a serem regulamentadas, nas quais todos os habitantes estão em contato direto e diário com a área urbana, existindo poucas exceções de contatos. A cultura nesse contexto passa a se difundir quando os que dela compartilham se deslocam, ou quando sua comunicação e os símbolos aí incluídos prevalecem sobre os de outras culturas em novos territórios. Além disso, outros fatores impeditivos como a própria questão legal do desenvolvimento local em áreas indígenas no território brasileiro, dificultam o seu entendimento e fomento.

A idéia de território deriva da conotação "terra", de substrato físico e material. No caso dos povos dos indígenas, a desterritorialização não está totalmente relacionada à exclusão do acesso a terra enquanto meio de produção e subsistência, mas principalmente a um patamar simbólico-cultural. Mesmo possuindo o domínio sobre um determinado território, pode faltar a sociedade indígena às referências territoriais de suas culturas, que constituem o próprio “imaginário geográfico" condensado simbolicamente em determinadas parcelas de espaços. Na realidade os espaços indígenas têm significados e significâncias, pois o espaço territorial é determinado em três partes: 1- o território ao redor da casa, destinado a responsabilidade da mulher; 2- o território de produção, destinado ao homem e 3- o território de perambulação, onde todos frequentam para caçar, pescar, banhar-se, desenvolver a espiritualidade e coletar.

Portanto, território para o indígena é ao mesmo tempo um espaço de reprodução física, de subsistência material e é um espaço carregado de referências simbólicas para a sua afirmação étnica e para se estabelecer as diferenças multiculturais no dito mundo globalizado. É necessário, portanto, combater a desterritorialização enquanto exclusão sociocultural e espacial de cada povo.

Nesse sentido, existem diversos conflitos quando se trata de questões territoriais, principalmente se comparados às concepções de terra e território entre os indígenas e o 


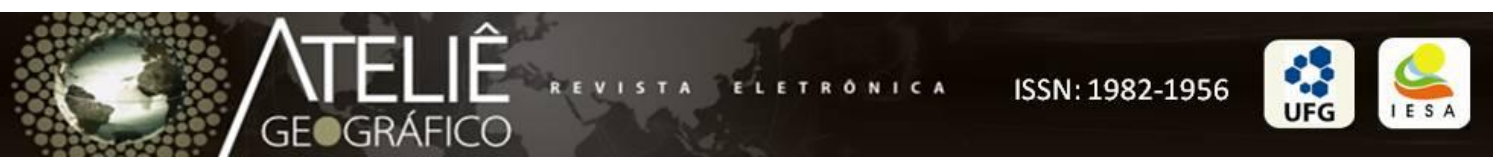

Estado, que não são as mesmas. Segundo Faria (2003, p. 04):

\begin{abstract}
A terra indígena, na visão do Estado, é um espaço homogêneo, meio de produção onde estão distribuídos recursos naturais. Na concepção indígena, terra é um mosaico de recursos naturais, morais e espirituais; seu território, além de conter dimensões cosmológicas, o que não ocorre na concepção de território do Estado. No entanto, território para o Estado é tão somente suporte material onde exerce seu poder e soberania.
\end{abstract}

A diferenciação entre os povos está relacionada também à língua como meio essencial de comunicação humana, sendo um componente crucial de qualquer cultura. A influência exata da língua sobre a cultura tem sido estimada, mas nunca estabelecida claramente. Seja como for, a língua, por sua vez, é fortemente afetada por outros aspectos de uma cultura. Quaisquer que possam ser estas interrelações, a linguagem de uma comunidade é uma de suas características distintivas. Uma cultura pode certamente abranger e sobrepor grupos linguísticos diferentes, mesmo que seja mantido algum tipo de equivalência entre os sistemas simbólicos coexistentes. A dominação vem pela exploração tanto econômica, quanto cultural. No caso da econômica verificamos que a ocupação territorial se dá pela produção capitalista. No entanto, a cultural, na maioria das vezes se dá pela religiosidade, envolvendo e estruturação da família, organização e ocupação do espaço.

No caso dos povos indígenas, esta diferenciação passa por um processo dialético instigados pela paisagem cultural com base na classificação regional que estimula uma visão sobre o papel do homem nas transformações geográficas e esclarece certos aspectos da cultura e de comunidades em si mesmas. Além disso, buscar diferenças na paisagem é atribuir diferenças de conduta humana sob diferentes culturas e procurar desvios de condições autóctones esperadas, causados pelo homem.

Compreendendo os mecanismos de diferenciação, de troca e padronização cultural, destacam-se dois fatos principais na história da cultura, idéias e técnicas tendem a se difundir e a herança cultural dos povos tende a aumentar cumulativamente. Tanto por evolução interna quanto por propagação, a cultura cresce e se dispersa. Quando se fala de “estágios”, portanto, não significa que um complexo substitua e elimine outro, mas exatamente, que aos velhos são acrescentados novos complexos e características culturais, que passam a coexistir. Eventualmente, podem surgir novos padrões, mas eles mantêm os mais velhos (ROSENDAHL e CORRÊA, 2003). 
Destacando que os saberes dos mais velhos nas comunidades indígenas são de fundamental importância para que o processo cultural seja mantido, tendo em vista que são os mais velhos que contam e recontam às histórias de antigamente, preservando o saber da sua comunidade e dos antepassados, tudo isso se dá através da língua materna de cada família, comunidade e povo.

Sob este aspecto, é oportuno afirmar que o próprio ato de produção altera não somente as condições objetivas, como por exemplo, transformando aldeias em cidade. Surgem também novas possibilidades de transformação para os territórios de modo que as relações possam, por conseguinte, conviver em uma situação paradigmática conforme estabelecido entre os novos e antigos padrões para o desenvolvimento do território. Um dos aspectos marcantes das transformações nos territórios indígenas está se projetando para abertura de novas oportunidades de desenvolvimento seja pela agricultura familiar, pela educação ou por formas de manifestação cultural como a dança, artesanato, musica, reza, indumentária, entre outros elementos culturais.

\section{O povo KAIOWÁ da RID - MS: contextualização}

No contexto social brasileiro o problema dos índios ganha notoriedade. Entre os muitos desafios que pesam sobre a análise destes, a questão da terra merece a atenção geral (WENCESLAU, 1990).

A população indígena de Mato Grosso do Sul-MS é hoje o segundo contingente populacional do Brasil, sendo superado apenas pelo Estado do Amazonas (FUNAI, 2010). Destaca-se que o MS compõe uma população indígena estimada em 50.000 índios aldeados e 5000 desaldeados, além de possuir diversos grupos étnicos diferenciados, como os Kaiowá, Ñandevá, Terena, Kadiwéu, Kinikinawa, Guató, Atikum, Ofaié e Camba (em processo de reconhecimento como povo brasileiro).

A RID, antes nomeada Posto Indígena "Francisco Horta Barbosa", está localizada na zona norte do município de Dourados. Distante a 3,5 km do centro urbano de Dourados, mais precisamente da Praça Antônio João e também a 8 km do município vizinho, Itaporã. A RID é cortada pela Rodovia MS-156 que liga Dourados a Itaporã no sentido Norte/Sul. Segundo dados da Fundação Nacional de Saúde - FUNASA (2009), conta com uma população de aproximadamente 12.000 indígenas, distribuídos em 3.539 
hectares. Na aldeia Bororó destaca-se a presença maciça dos Guarani dos troncos Kaiowá e Ñandeva e na aldeia Jaguapirú, encontram-se a comunidade Terena, uma pequena população Nandeva e Kaiowá, além dos mestiços que se fazem presentes em ambas as aldeias.

As terras da RID estão tituladas de acordo com o Decreto n ${ }^{\circ} .404$ de 03/09/1917 e registradas às folhas do livro $\mathrm{n}^{\mathrm{o}}$. 23, em 14/02/1965, no Cartório de Registro de Imóveis de Campo Grande em 26/11/1965, conforme despacho do Secretário de Agricultura do Estado de Mato Grosso de 23/11/1965 (MONTEIRO, 2003). A referida área somente teve seu Título Definitivo de Propriedade expedida em 28/10/1985 e seu registro em 14/12/1985.

Os grupos existentes na RID se diferenciam em diversas dimensões culturais, tanto por sua origem como por sua representação a partir da ocupação do próprio território no município de Dourados. Cada povo possui seus traços tradicionais e, ao mesmo tempo, diferentes fases de adaptação estimuladas pelo contexto socioeconômico e cultural do entorno.

Existe uma complexidade do significado ligado às paisagens para incorporar as expressões dos modos de vida do passado do Kaiowá, assim como do presente, exigindo estudos detalhados sobre o local estudado. As paisagens contêm significados culturais residuais e emergentes, assim como atuais. Neste trabalho restringe-se apenas a analise do recorte das questões históricas que refletem diretamente no desenvolvimento cultural do povo Kaiowá da RID.

O povo indígena Kaiowá da RID, vive de certa forma desterritorializado, baseado nos apontamentos teóricos de Haesbaert (2001), tanto no sentido social ligado às questões da miséria, da desnutrição, da falta de terra, aumento acelerado dos povos, do suicídio, como sobre os aspectos culturais relacionados ao aspecto religioso com a introdução de dezenas de igrejas evangélicas na RID, na dança com a expansão da musica eletrônica, na gastronomia com os hábitos e costumes do entorno.

A RID compreende uma complexa área de estudo podendo ser colocada como uma reflexão a respeito da formação histórica e geográfica, considerando os fatores que implicaram na massificação e degradação local que provocam impactos negativos na natureza, nas culturas indígenas sendo principalmente relacionada à ocupação territorial, 
distribuição das terras, aumento populacional, extermínio da mata nativa essencial para subsistência, indumentária, artefatos, entre outros e a interferência da comunidade do entorno sobre as questões político-administrativas.

Nesse sentido, analisa-se, portanto as modificações e interferências no modo de ser e viver Kaiowá estimulados principalmente em função dos aspectos econômicos gerados pelo modo de produção capitalista e na maioria das vezes com a anuência da FUNAI. Os efeitos gerados nas comunidades tradicionais são decisivos pela reconfiguração seus valores pessoais e comunitários que possibilitam uma dependência de ações afirmativas e assistencialistas exógenas, principalmente promovidas pelas políticas públicas vigentes.

\section{A tradição indígena na linha do tempo: passado e presente}

Sabe-se que a palavra tradição vem do latim, do verbo "tradere" (traditio, traditionis) que significa trazer, entregar, transmitir, ensinar. Desta forma, a tradição pode ser entendida como a transmissão de fatos culturais de um povo, quer seja de natureza espiritual ou material. Em muitos casos pode ser transmitida por meio dos costumes passados de pais para filhos no decorrer dos tempos, ao sucederem-se as gerações que são imbuídas de um conjunto de idéias, usos, memórias, recordações e símbolos conservados pelo tempo. O termo tradição, tal como é usado atualmente, é na verdade um produto dos últimos duzentos anos na Europa. A idéia de tradição, portanto, é ela própria uma criação da modernidade (GIDDENS, 2000).

Apesar de não ser considerada uma ciência de fato, a tradição está dividida em duas formas conhecidas: a histórica e a popular. A primeira se destina a transmissão da memória de fatos ou de aspectos importantes, preservada por meio de documentos (cartas, biografias, arquivos, calendários, anais entre outras formas) e monumentos (túmulos, palácios, obras de arte, brasões, esculturas, moedas e outros), podendo também ser discutida através das análises dos registros existentes. Já a segunda, a tradição popular, reserva-se ao registro dos fatos culturais que são conservados pela oralidade ou mesmo pela aceitação coletiva do povo (BARBOSA LESSA, 1983).

Mesmo as tradições conhecidas como a passagem de hábitos e costume de geração para geração, na atualidade, os indivíduos estão renovando suas idéias e vendo os acontecimentos com outros olhos. Mesmo as sociedades mais tradicionais, como 
aquelas relacionadas ao aspecto religioso, vêm procurando se adequar para atender as mudanças provocadas no meio social e cultural, como por exemplo, as congregações evangélicas que antes possuíam uma conduta rígida e conservadora, hoje são mais flexíveis e modernas.

Nesse contexto, a tradição assume vários papéis importantes para os povos, seja na constituição da forma original ou como também caracterizada por alguns autores de “invenção" (HOBSBAWM E RANGER, 2006). O termo está relacionado aos recortes históricos que possuem seus fatos e acontecimentos que determinaram seu sistema de conduta e regência administrativa. Para tanto, observa-se que em vários episódios históricos as tradições que parecem ou são ditas como antigas, são bastante recentes, quando não são em sua maioria, inventadas.

Como ponto de partida é importante entender que a realidade social de um povo é baseada na tradição, transmissão de atitudes, valores, mudanças e evolução. Têm-se como exemplos a religião e as ideologias, que vem assumindo papel fundamental na compreensão do pensamento sociológico concebido por meio de um conjunto de sentidos, valores, representações e simbologias. E, dentro deste universo de diferenciação de produções tangíveis ou imateriais de saberes, deve-se levar em consideração uma premissa que está diretamente intrínseca e que diz respeito à questão identitária de cada povo. Tem-se que cada grupo social se diferencia nos hábitos e costumes, mesmo porque, como aponta Claval (2009, p. 12): “As sociedades não são homogêneas".

Nessa diferenciação entre hábitos e costumes, Giddens (2000, p. 51) enfatiza:

As tradições são sempre propriedades de grupos, comunidades ou coletividades. Indivíduos podem seguir tradições ou costumes, mas as tradições não são uma característica do comportamento individual do modo como os hábitos o são. O que a tradição tem de distintivo é que ela define um tipo de verdade. Uma pessoa que segue uma prática tradicional não cogita de alternativas.

Sob este aspecto, é oportuno incluir breves considerações a respeito do texto $a$ política de reconhecimento de Charles Taylor (1998), que propicia uma ampla reflexão a respeito da política de igualdade e diferença em nome dos grupos marginalizados - e aqui se adiciona os povos indígenas, foco de estudo. Ressaltam-se como eixos norteadores de discussão uma tríade de elementos subjetivos que compõe o indivíduo 
com base na construção da identidade, estabelecendo, consequentemente, a autenticidade e originalidade por meio da noção de individualidade.

Enquanto Taylor trabalha a identidade como política de reconhecimento, Castells (1999, p.231) desenvolve sua tese por um viés sócio-cultural de construção identitário. Para ele, essa deve ser entendida como o "processo de construção do significado com base em um atributo cultural ou ainda um conjunto de atributos culturais inter-relacionados, $\mathrm{o}(\mathrm{s})$ qual(is) prevalece $(\mathrm{m})$ sobre outras fontes de significado". Estes significados são reconhecidos pelas manifestações culturais materiais e imateriais, cuja tradição estabelece o elo do passado com o presente.

Castells (1999) assegura ainda que a identidade só é construída por meio de mecanismos fornecidos pela história, geografia, biologia e memória coletiva. Para ele estes aparatos mostram-se como determinantes para a formação do conteúdo simbólico, tomado de maneira particular ou coletivizada. É através da formação ou reconstrução da identidade de um povo que se pode fazer valer o respeito pela diversidade e alteridade étnica, mesmo sob a tendência de homogeneização promovida pelo atual sistema econômico. Segundo Suess (1995, p.71) a alteridade pode ser entendida como a "Diferença e diversidade constitutivas de identidade. É a arma de resistência mais eficaz do pobre. A alteridade é o muro que separa o colonizador do santíssimo dos povos colonizados".

Neste momento, vale destacar a visão de Claval (2009), cujo argumento assegura que a sociedade é uma entidade que se auto-reproduzam e ao mesmo tempo, muda. Segundo Claval (2009, p. 16): “A auto-reprodução repousa sobre a exploração dos recursos para satisfazer as necessidades humanas, sobretudo à reprodução biológica e a transmissão dos saberes e crenças de uma geração para outra". A necessidade de se transformar constantemente é uma realidade vivida pelos indivíduos há muito tempo e servem para atender tanto os desejos pessoais como as tendências do ambiente externo.

Desta forma, tem-se que a reprodução material provocou à divisão do trabalho e consequentemente a formação de classes. $\mathrm{O}$ enriquecimento da classe burguesa e o crescimento acelerado da mecanização conduziram ao atual e conhecido modo de produção capitalista. De acordo com a visão marxista, o sistema de trabalho era pago por seu valor de troca e não por seu valor real, ou seja, o capital enriquecia-se a custa do trabalho, resultando no empobrecimento dos operários e na formação de um 
proletariado cada vez mais excluído da sociedade. Assim, o ideário de união social parecia como algo cada vez mais distante, como um disfarce a realidade e impossível de se concretizar de fato (CLAVAL, 2009).

Neste sentido, as transformações socioeconômicas ocorridas com o advento do capitalismo potencializam o pensamento que modifica a natureza e os seres humanos em produção e, por conseguinte, o ambiente em mercadoria. Comparativamente, em detrimento a questão de renovação e fortalecimento de representações sociais que se alternam mediante os processos econômicos e culturais, cita-se também como exemplo o processo de globalização. Este promove aceleradamente um desenvolvimento aparentemente renovado, que se apóia em um planejamento dito estratégico e sustentável, para alcançar as metas de legitimar as práticas de acumulação, homogeneização cultural e reprodução do capital (Idem, 2009).

A essas fronteiras da desigualdade e exclusão incluem-se principalmente as comunidades indígenas, além é claro, das classes menos favorecidas que habitam cortiços, favelas, reservas e vilas no território nacional brasileiro. Não se evidencia o multiculturalismo arraigado nas alteridades encontradas nos grupos sociais diversos com sua exclusão ao direito a cidadania e dignidade de acesso as necessidades básicas como moradia, saúde, educação, cultura e lazer.

As transformações sociais, econômicas e culturais vivenciadas desde os primórdios da humanidade, promovem diversas indagações: Como se constitui a identidade de um povo? A tradição é um elemento que se perpetuará ou estará a cada momento reconfigurado para atender as necessidades do sistema econômico e, consequentemente, para sobreviver a estas tendências? Existe uma tradição autêntica ou nada mais é do que uma "invenção" (como apontados por HOBSBAWM e RANGER, 2006) como forma de transmitir o conhecimento gradativo acompanhando as interferências sociais?

Os questionamentos acima evidenciados permitem perceber que cada vez mais as pessoas vêm sofrendo reflexos marcantes promovidos pelo ambiente em que estão inseridas. No primeiro questionamento vale lembrar que a identidade de um povo é cíclica e mesmo com as interferências externas, existem os apegos simbólicos constituintes de cada cultura. Já a segunda indagação, é difícil de prever se existirá uma homogeneização generalizada da cultura, acredita-se que não, porém é indiscutível que 
para mantê-la é preciso se adequar a evolução do sistema econômico. Portanto, a necessidade de identificar se uma tradição é inventada ou não, perde seu valor na medida em que a autenticidade está, muitas vezes, relacionada aos próprios critérios adotados pelo grupo social. Existe, entretanto, a manipulação da tradição, que passa a ser um instrumento utilizado por determinados grupos com o fim de se apropriarem da garantia de manutenção do sistema capitalista. Porém, o poder simbólico e cultural sempre será o antídoto para dar a tônica necessária entre o antigo e o novo, bem como, para entender o processo de tradicionalização e, por conseguinte, de sobrevivência existencial.

\section{O passado e o presente da comunidade Kaiowá da Rid}

A nomenclatura referente ao tronco linguistico Guarani, em seu subgrupo Kaiowá, a exemplo de outros aspectos de sua tradição de conhecimento, é tema de difícil abordagem dada a variedade de nomes que podem assumir. Há uma enorme lista de nomes utilizados para designar os povos dessa "nação", que se agrupavam, segundo descrição dos primeiros colonizadores, em pequenos grupos ou divisões que tomavam o nome do líder político-religioso local ou, ainda, o nome do lugar por ele ocupado. Sob uma mesma denominação podiam ser identificadas diferentes "comunidades" que viviam ao longo de um rio ou próximo de fontes de água e mato, assumindo, cada uma delas, denominação particular, razão pela qual há uma diversidade muito grande de nomes dados aos Guarani pelos conquistadores (SCHMITZ, 1982).

A população não indígena do Paraguai, que fala a língua guarani, refere-se aos Guarani pelo termo ava (homem Guarani), também utilizado pelos subgrupos que vivem no país. No Brasil os termos "paisano" ou "patrício" também são utilizados pelos indígenas no discurso com o não-indígena ao referir-se a outros. No estado de Mato Grosso do Sul e em toda a região sul do país estes e outros grupos étnicos são genérica e depreciativamente chamados de "bugres", termo que deve ser evitado por carregar uma concepção preconceituosa talvez pelo atual modo de vida que se encontram os povos indígenas (SCHMITZ, 1982).

Os Guarani-Kaiowá acreditam que foram os primeiros criados por Deus, Ñande $R u$, "nosso Pai", ou Ñande Jára, "nosso Senhor", considerando-os como verdadeiros e autênticos em relação ao mundo dos não-indígenas e dos outros Guarani (MANGOLIM, 
1993). Complementando a idéia, Wencelau (1990, p. 95) diz:

(...) ser Kaiowá é ter uma história própria e particular, não apenas uma história factual e temporal, mas também uma história factual, porém atemporal: uma época localizada no 'antigamente', no 'tempo primeiro' quando surgiram os Kaiowá. Este é o tempo dos mitos onde a dimensão linear do tempo não é necessária, mas faz sentido. É o tempo onde aprenderam a ser o que são, onde lhes foi ensinado a ser, que animal comer, como morar, a dividir o tempo, como se relacionar com os deuses.

O sudoeste sul mato-grossense e o Paraguai oriental, que se confundem, hoje, com territórios Kaiowá e Ñandeva, estiveram isentos de processos colonizadores intensos até o começo do séc. XX e teria sido um "refúgio" para a nação Guarani. A partir da última década do séc. XIX e até as duas primeiras do séc. XX, grandes partes dos territórios Guarani foram alvo de mobilização exploratória da erva mate, promovida por empresas detentoras do monopólio desse produto em região que abarca os atuais estados do Paraná, hoje Mato Grosso do Sul no caso brasileiro, e nos países vizinhos, como o norte da Argentina e o Paraguai oriental. Com poderes para impedir a entrada e permanência de colonos ou concorrentes, o arrendamento contribuiu para manter as áreas sob o controle destas empresas, livres de colonos até as décadas de 20 e 30. Conservaram-se em grande medida as matas e nelas se mantiveram os Guarani. Os Kaiowá sofreram diretamente o impacto da guerra, na medida em que eram eliminados pelas tropas dos dois exércitos, pois se recusavam a sair de suas terras, que foram transformadas em verdadeiros campos de batalha pelas tropas brasileiras e paraguaias (ALMEIDA, 1996).

Os Kaiowá não podem ser entendidos comumente como uma etnia indígena. A denominação Kaiowá é um produto da dominação colonial que não sabia distinguir as diferentes formas de ser Guarani. Essa heterogeneidade entre os grupos foi registrada pelos diferentes cronistas ao longo do processo de contato mantido com esses índios desde o século XVI.

Na concepção do capitão Ireno Isnard (1991) apud Meihy (1991, p. 39):

Kaiowá e guarani é quase a mesma coisa...éramos um só bando que se partiu... um grupo sai do Paraguai e veio primeiro para o Mato Grosso, estes são os Kaiowá...depois vieram alguns guarani para cá... Somos filhos de Ñhanderú e Ñhandesi e Ñhanderamoue é nosso protetor... é o protetor da mata...Kaiowá quer dizer filho da floresta, da madeira, da mata...Kaiowá é a natureza... protegido de N̂handeramoe... em guarani a gente fala txe-dja-ri... 
Os Kaiowá nunca foram uma unidade com um único chefe. O poder político estava diretamente relacionado com as lideranças religiosas e que estavam em cargo dos chefes das grandes famílias. Hoje a situação mudou um pouco, porque as lideranças estão em formação. Portanto, a situação atual é de liderança única através do capitão, sendo este eleito pela comunidade. Segundo Rasslan e Wenceslau (1991, p. 32): "Isso ocorria, pois quanto maior a família, maior o prestígio de ser líder, que obtinham ampliação, se fosse um grande Pai cantador e curador". Assim, o poder estava dividido. Com a penetração das frentes econômicas da sociedade nacional em sua área, um desses líderes passou a ser escolhido para servir de intermediário entre os Kaiowá e nãoindígenas, recebendo posteriormente o título de capitão. Para Wenceslau (1990, p. 96): “O território faz parte não do sistema de identificação dos Kaiowá, mas o sustentáculo do lugar onde se realiza esta sociedade.

A situação atual tem características próprias, porque não possuem lideranças formadas. Na realidade, ainda em formação pelos mais velhos, sendo estes jovens informados e formados para desencadear o processo de liderança, tanto pela formação espiritual, medicinal e política.

\section{Hábitos}

Os Kaiowá, em geral, possuem estatura maior que os Ñandeva. Sua alimentação baseia-se tradicionalmente no milho, mandioca e nos dias atuais o arroz. Elaboram a chicha, uma espécie de bebida fermentada derivada do milho ou da batata doce para complementação de sua alimentação bem como para os rituais e festas. Utiliza-se de ervas medicinais para o controle da natalidade, espaçando o nascimento dos filhos, que geralmente acontecem a cada dois anos. Para eles, não existem crianças abandonadas, pois quando acontece de uma família rejeitar o filho, outra família adota-o, mas com tratamento diferenciado dos filhos legítimos e são denominados como "guachos".

Segundo Mangolim (1993, p. 19):

(...) Até cerca de 20 ou 30 anos atrás, os Kaiová moravam em casas grandes (Ogajekutu, Ogaguasu), reunindo até 100 pessoas da mesma família grande. Hoje estas Ogajekutu cederam lugar a casas geralmente pequenas abrigando apenas a família nuclear, embora mantendo a proximidade territorial com os demais membros da família extensa (pais, filhos, genros, etc...) que, segundo 


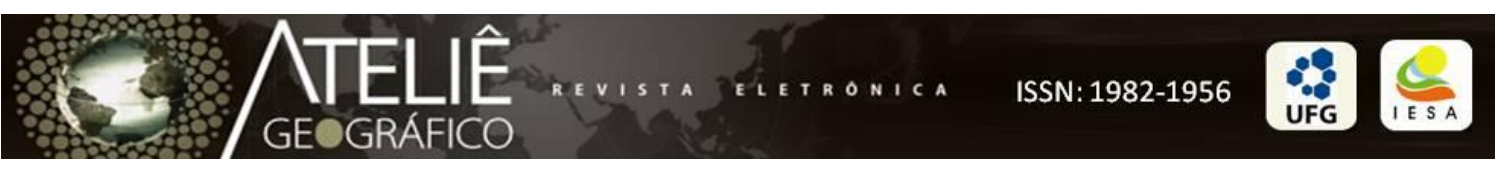

o antropólogo (padre jesuíta) Meliá, continua sendo a base organizacional dos Kaiová”.

Para o autor, nesta organização, a autoridade é a pessoa de maior prestígio, geralmente homem e líder religioso. Seus valores são outros, sua política é outra, pois sua essência está baseada na família extensa, cuja chefia se baseia no prestígio e na religiosidade. É no tekohá que se confundem e fundem terra, território, subsistência, relações sociais e festas religiosas que dão significado à produção das inter-relações entre o meio social, econômico, político e religioso, essenciais para a sua sobrevivência (OLIVEIRA, 1998).

\title{
Subsistência
}

Para o Capitão Ireno Isnard apud Meihy (1991, p. 41), líder Guarani, a terra é o sustentáculo de sua comunidade, demonstrando o alto nível de exploração e o não respeito do outro para com o seu povo. Segundo ele:

\begin{abstract}
Antigamente a vida também era difícil... mas para o índio a vida nunca foi fácil... antes não tinha todas essas coisas do branco que tem hoje... índio plantava para comer... e conseguia as coisas que precisava por aí... A terra era grande... tudo isto aí era do índio e ele podia pegar o que quisesse dela... Com a chegada dos primeiros fazendeiros os índios começaram a aprender o gosto de outras coisas: sal, café, carne, sabão... estas coisas nós aprendemos depressa, coisas boas, não é?!... Havia uns poucos fazendeiros por perto e a gente se dava bem... eles davam alguma coisa que a gente precisa... foi bom enquanto eles ficaram para lá, e nós para cá... mas, tenho que dizer que com os brancos vieram muitos problemas... não foram só coisas boas que aconteceram, não!... Como existia muita terra, nós índios podíamos viver mais livres... ah!... aqui era uma mata só... e nós um punhadinho de famílias... Naquele tempo o índio podia ir solto por aí... andar de lá para cá... era tão diferente!... Tinha coisa boa, apesar da gente não ter o sal, o sabão... mas a comida não faltava enquanto a gente estivesse trabalhando na terra... Índio precisa de terra... de terra grande, viu?
\end{abstract}

A terra é para o Kaiowá suporte de sua identificação étnica, constituindo-se em um elemento básico para a sua vida. O uso da terra passou a ter um sentido comunitário, e não especulativo, justificando o sistema de cultivo rotativo que permitia à mesma comunidade permanecer por várias gerações dentro de um mesmo perímetro relativamente reduzido (RASSLAN e WENCESLAU, 1991). Hoje, identifica-se na RID muitas dificuldades sendo enfrentadas pela falta possibilidade de produção alimentar, 
sendo que a população alijada da possibilidade de um espaço para o cultivo e um grande número de famílias se deslocando para a área urbana, desta forma, buscando também emprego.

É necessário admitir que sem terra e o tekohá não seja possível a conservação cultural dos povos indígenas. É ela que estabelece uma inter-relação dos espaços, observando: o espaço para perambulação, o da roça e o mais importante, a aldeia. Com o aumento populacional verificamos que os espaços estão reduzidos e a área de perambulação na RID é inexistente.

\section{Danças e Festas}

As danças e as festas são características peculiares da cultura indígena, onde as manifestações tradicionais são evocadas para dimensionar o ser e o modo de viver na essência étnica através de do seu território. Os Kaiowá acreditam que a terra foi dada a eles por Deus. Segundo o capitão Ireno apud Meihy (1991, p. 44):

\footnotetext{
Nós kaiowá acreditamos que a terra foi dada por Deus para nós e agradecemos a ele... para isso dançamos a chicha... antes a chicha era um jeito de rezar, de falar com Deus...hoje não é mais assim...agora a chicha é uma dança igual à dos brancos...tem até pinga quando se dança a chicha de agora...
}

Um pouco mais adiante do depoimento do capitão Ireno apud Meihy (1991, p.46) ele diz:

\footnotetext{
Hoje nós não vamos muito nas festas porque se passa a noite e perde o sono e depois não dá para trabalhar no dia seguinte...também agora nas festas tem muita pinga e índio bêbado é uma coisa triste demais...a festa de agora é só para bebedeira e sai muita briga, não dá mais para a gente ir...
}

As festas continuam, algumas dentro da característica original e outras dentro da cultura do não indígena. Mesmo com a entrada de bebidas alcoólicas na RID, apontada como uma das responsáveis pela mudança dos hábitos tradicionais, ainda se vê in loco que existem as manifestações culturais por meio das dança e festas entre os povos kaiowá, que realizam suas reuniões que duram em média três dias, onde traços da indumentária, do artesanato, da culinária, da dança sobrevivem para contar a seus descendentes o verdadeiro sentido do ser indígena. Hoje, as festas são feitas, porém em 
menos quantidade, são mantidas apenas as apresentações públicas onde o grupo recebe uma pequena quantia em valor por apresentação.

\section{Religião}

O sistema religioso dos Kaiowá tem uma estrutura de prestígio. O grande objetivo deste Kaiowá é ser um $\tilde{N} a n d e ~ R u$, ou seja, um rezador, um líder religioso, o que consequentemente lhe confere uma posição de prestígio e de governo sobre a comunidade que tem o poder de decisão democrática. Nas grandes reuniões, chamadas de Aty Guassu,, onde todos os kaiowá tem o direito de expressar suas opiniões, os rezadores tem papel importnte, porque toda decisão são tomadas através das discussões e rezas.

A organização político-administrativa autoritarista sobre os indígenas, principalmente a partir da criação do Serviço de Proteção aos Índios SPI e depois com a Fundação Nacional do Índio - FUNAI impuseram o confinamento, dos Kaiowá e todos os indígenas no Brasil, em pequenas áreas, sem levar em consideração a essência das diferenças de cada povo e cada comunidade, por meio das famílias extensas, ou seja, muita aldeias, num único espaço, tekohá, considerando que o espaço territorial (Tetã) é elementos vital para sua existência enquanto organização familiar e social.

Segundo Mangolim (1993, p. 21):

Como o Guarani situa sua vida num espaço essencialmente mítico-religioso, absorveu estes elementos com uma passividade difícil de ser entendida pela não índio. Mas tratou de se defender como pode: escondeu os seus rituais, camuflou o prestígio visível do Ñande Ru e submete-se às formas de organização impostas de fora para sobreviver.

No depoimento a respeito de vida tradicional, complementa a vida tradicional do atual como comprova o índio Albino Nunes apud Meihy (1991, p.46):

A religião da gente era diferente: tinha cantos, danças, o povo participava...quando nos reuníamos para rezar era concorrido, mas agora está fraco...na época que eu era criança sempre rezávamos com os mais velhos, com os pajés... as pessoas importantes da família se juntavam, principalmente nos fins de semana, e faziam o culto...Haviam também situações especiais para se fazer a reza... quando alguém estava doente, por exemplo, tinha uma pajé que vinha tomar conta... e não era qualquer um, para cada problema tinha uma pessoa...esse pajé trazia as ervas do mato e rezava, rezava... até o índio sarar... Hoje, quando alguém fica doente, já estão preferindo levar para 


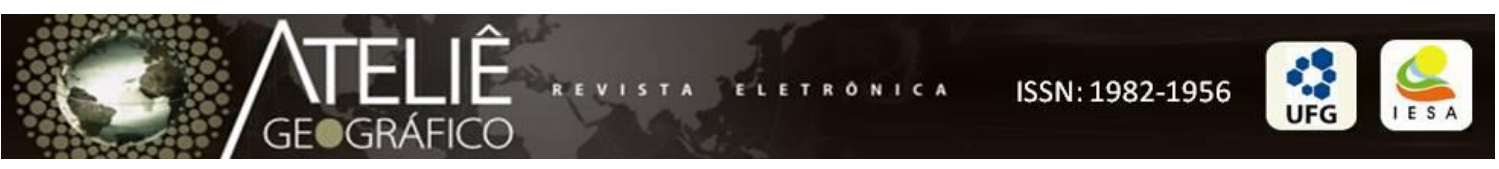

o hospital da Missão ou para o posto médico, em vez de fazer reza... mudou muito...

Considerando as interferências provocadas no meio tradicional em função do capital, os aspectos religiosos foram os primeiros a sofrerem tais impactos, pois se vinculam as novas seitas e religiões que numa forma de catequizá-los, provocam alterações no modo de ser e compreender sua existência enquanto indivíduos na sociedade indígena e envolvente. Desta forma, os aspectos religiosos vividos pelos indígenas com o passar do tempo, mesmo com tantos conflitos gerados por questões socioculturais, os Kaiowá estão conseguindo revitalizar, como instrumento de luta, seus principais valores tradicionais: a religião, a autoridade religiosa, familiar e comunitária.

\section{Considerações finais}

A análise subjetiva do território e por extensão a questão imbricada na tradição de povos indígenas, pode ser assinalada por uma soma de representações de como estes povos concebem e reconhecem a sua importância cultural, histórica e social diante da sociedade a quais estão vinculadas ao preconizar o caráter territorial como um espaço em que perpetua a história vivida. Logo, é imperativo condicioná-lo a fundamentos que incitem o despertar de uma interpretação que contemplem tais questões ao abordar o caráter de litígio histórico, que atribua um sentimento de pertença ao grupo e ao espaço.

O território se configura como um espaço indissociável das relações entre pessoas e pessoas, pessoas e ambiente vivido, cuja compreensão do todo deve considerar a interdependência entre natureza e ação humana, uma vez que revela ações passadas e presentes, apresentando-lhe um sentido de pré-existência contida principalmente na formação da territorial ao perpassar pelo viés da tradição. E por este prisma, nada mais justo que incluir a concepção que os povos Kaiowá têm de si enquanto comunidades culturalmente importantes para a formação de uma sociedade historicamente estabelecida.

Diante deste argumento, afirma-se que o sentido de território passa a existir como um tecido social carregado de história e tradições, cuja herança e vínculos culturais assumem função importante para construir condições que fomentem a criação 
de variáveis para sua transformação, tendo em vista que as ações humanas são passíveis de modificações ao longo de sua trajetória histórica e pessoal.

A análise do território conduz a uma reflexão sobre a sua constituição para o ser humano, quando ele o constrói como um lugar carregado de emoções e racionalidade, ao qual embute sentido e abstração do conhecimento advindo de seu meio físico, sóciocultural e histórico.

A realidade dos povos indígenas apresenta um marcador de território e tradição que são bem peculiares. Trazendo à luz de discussão, julga-se pertinente apresentar o que pode muito bem condizer com a formação destes grupos, na medida em que procuram relacionar e desenvolver suas atividades em espaços físicos bem delimitados, que por sua vez, tais traços carregam características significativas para o grupo em que o habita por manter uma descrição das gerações passadas. Ou seja, permite compreendêlo como um espaço territorialmente formado pelos efeitos das transformações ambientais e culturais e consequentemente, promove um sentimento de pertença.

Nesse sentido, a cultura indígena de Mato Grosso do Sul é baseada na genealogia, cujo aprendizado do conhecimento é constituído a partir da criação até o presente. $\mathrm{O}$ aprendizado do conhecimento começa, portanto, a partir dos deuses, dos heróis, dos ancestrais através de seus pais, avós e parentes, entre o início de tudo e a geração atual.

Os povos indígenas têm conhecimento de sua cultura desde sua criação, juntamente com as histórias associadas a cada nível da genealogia e à criação que os integrou em um mundo natural, onde a terra é concebida como o centro do universo. Eles vêem a si próprios olhando o passado, sempre orientados pelo passado, que é a realidade conhecida: o presente, o passado imediato e o passado até o início da criação.

Portanto, eles se vêem entre o passado, adquirindo conhecimentos antigos para desencadear o caminho para o futuro, enquanto o presente continua confuso, no entanto com a volta da importância dos rezadores e lideranças em formação o passado, presente e futuro, colaboram para a formação dos povos indígenas se preparando para as novas situações e visão de mundo, em busca das terras tradicionais.

\section{Referências bibliográficas}


ALMEIDA, R. F. T. O caso Guarani: o que dizem os vivos sobre os que se matam? In: RICARDO, C. A. (Ed.). Povos Indígenas no Brasil: 1991/1995. São Paulo: Instituto Socioambiental, 1996.

BARBOSA LESSA, L.C. Caráter cíclico do tradicionalismo. Porto Alegre, 1983.

CASTELLS, M. O poder da identidade: a era da informação: economia, sociedade e cultura. V.2. São Paulo: Paz e Terra, 1999.

CLAVAL, P. Globalização, migrações, inclusão e exclusão: algumas reflexões. In: ALMEIDA, M. G \& CRUZ, B. N. Território e Cultura: inclusão e exclusão nas dinâmicas socioespaciais. Goiânia: UFG, 2009, p.10 - 25.

GIDDENS, A. Tradição. In : O mundo em descontrole : o que a globalização está fazendo de nós. Tradução de Maria Luiza X. de A. Borges. Rio de Janeiro: Record, 2000. p. 47-60.

HAESBAERT, R. Da desterritorialização à multiterritorialização. In: Anais do IX Encontro Nacional da ANPUR. vol. III. Rio de Janeiro: ANPUR, 2001.

Concepções de território para entender a desterritorialização. In: SANTOS, Milton (org). Território territórios. Niterói: Pós-Graduação em Geografia: UFF, 2002.

HOBSBAWN, E. \& RANGER, T. A invenção das tradições. 4 ed. Tradução de Celina Cardim Cavalcante. São Paulo: Editora Paz e Terra, 2006.

FARIA, I. F. Território e territorialidades: indígenas do Alto Rio Negro. Manaus: Editora da Universidade Federal do Amazonas, 2003.

MANGOLIM, O. Povos indígenas no Mato Grosso do Sul: viveremos por mais 500 anos. Campo Grande: Conselho Indigenista Missionário Regional de MS, 1993.

MONTEIRO, M. E. B. Levantamento histórico sobre os índios Guarani Kaiowá. Rio de Janeiro: Museu do Índio, 2003.

OLIVEIRA, S. G. G. de; BRAND, A.; GUIMARÃES, L. A. M. Vida e morte na cultura Guarani/Kaiowá. Multitemas, Campo Grande: UCDB, 1998.

OLIVEIRA, C. M. Uma etnologia dos índios misturados? Situação colonial, territorialização e fluxos culturais. Mana - estudos de antropologia social. PPGAS/MN/UFRJ, 4/1, abril, 1998.

RASSLAN, I. N.; WENCESLAU, M. E. (orientadora). O índio e a comunidade de Dourados. Dourados: UFMS, 1991. Dissertação de Mestrado.

ROSENDAHL, Z. e CORRÊA, R. L.(orgs). Introdução a geografia cultural. Rio de Janeiro: Bertrand, Brasil, 2003.

SCHMITZ, P. I. El Guaraní en Rio Grande do Sul: la colonización del Monte y los frentes de expansión. Estudos Leopoldenses, São Leopoldo: Unisinos, 1982. 
SANTOS, M. O dinheiro e o território. In: SANTOS, M. (org). Território territórios. Niterói: Programa de Pós-Graduação em Geografia: UFF: AGB, 2002.

SUESS, P. Evangelizar a partir dos projetos históricos dos outros: ensaios de missiologia. São Paulo, 1995.

WENCESLAU, M. E. O índio Kaiyowá e o Mundo dos Brancos. Dissertação de mestrado, USP, 1990.

. O índio Kaiyowá: suicídio pelo Tekohá. Tese de doutorado, USP, 1994.

Recebido para publicação em outubro de 2010

Aprovado para publicação em dezembro de 2010 